EGU2020-13153, updated on 30 Mar 2021

https://doi.org/10.5194/egusphere-egu2020-13153

EGU General Assembly 2020

(c) Author(s) 2021. This work is distributed under

the Creative Commons Attribution 4.0 License.

\title{
Poking holes in discharge time series with photographic evidence
}

\author{
Anthony Michelon ${ }^{1}$, Gilles Antoniazza ${ }^{1}$, Natalie Ceperley ${ }^{1}$, Stuart Lane ${ }^{1}$, and Bettina Schaefli ${ }^{1,2}$ \\ ${ }^{1}$ University of Lausanne, IDYST, Lausanne, Switzerland (anthony.michelon@unil.ch) \\ ${ }^{2}$ University of Bern, Institute of Geography, Bern, Switzerland
}

River discharge is a key variable for hydrological studies and water resource management, but acquiring high-quality measurement remains challenging in mountain environments and in particular for mountain torrents. Extreme discharge variations between summer and winter, negative temperatures and intense sediment transport are the main issues for sensors (that get easily clogged, frozen or stucked out of the water) as well as for cross-section stability (a precondition for using a rating curve approach).

In this presentation, we discuss what we learned from streamflow observations in the experimental Vallon de Nant catchment $\left(13,4 \mathrm{~km}^{2}\right)$, located in the Swiss Alps, which serves as a field laboratory for environmental research, ranging from plant ecology to snow hydrology and sediment transport to stream-C02 exchange with the atmosphere. We discuss here 4 years of optical height gauge records at the outlet (1200 m a.s.I.), obtained from a single VEGA-PULS WL-61 sensor measuring the water height above a concrete trapezoidal shaped cross-section (base width $5.3 \mathrm{~m}$ ), designed primarily for sediment transport observations (with 10 geophones mounted flush on the concrete weir). There was no low flow channel within the cross-section. At least four other similar gauging stations are currently in use for hydrologic research in Switzerland, with or without low flow channels. The relevance of a discharge quality study at this site is twofold: i) to understand the reliability of flow measurements during low flow and during sediment-influenced high flow events and ii) to compile recommendations for similar discharge observation settings.

At the Vallon de Nant study site, the absence of a low-flow channel in the weir, combined with the limitation of having a single river stage measuring point resulted in significant over- and underestimation of the river stage at low-flows, caused by the fluctuation of the river bed position relative to that of the measuring point. Even if the flow covers the entire width of the weir crest, single clast deposits near to the crest can significantly disturb stage observations. We performed a validation of the data using hourly pictures taken during daytime with a low-cost camera at the outlet, and used the photographic evidence to identify periods when the river was partially or totally frozen, sediments were distorting the river stage measurements, and river channelization was occurring below or next to the river height sensor. Concurrent monitoring of temperature, conductivity or turbidity failed to identify these distortions. Consequently, significant error in discharge calculation would arise without a concurrent photographic observation. The key conclusion is that despite the growth of automation in measurements at gauging stations, there remains a need for observation of those stations, and if humans are no longer doing these, other 
digital technologies such as imaging need to be used instead. Our approach could be extended to night-time situations and locations that will go for extremely long periods without access. 